\title{
Tooth eruption disorders associated with systemic and genetic diseases: clinical suide
}

\section{Choukroune}

\begin{abstract}
Qualified specialist in Dentofacial Orthopedics, former Hospital Resident, private practice in Boulogne-Billancourt
\end{abstract}

\section{SUMMARY}

Tooth eruption is defined as the movement of the dental root and the tooth from its original development site in the alveolar process to its functional position in the oral cavity. Despite vast amounts of research, the exact mechanism of tooth eruption remains unknown. The authors have shown that the dental crown is not necessary for tooth eruption, whereas the dental follicle seems to be essential for the process. The formation of an eruption pathway by bone resorption allows the root to breach the oral cavity, at the same time, bone formation occurs at the basal level of the dental root. Multiples genetic and molecular structures coordinate these events. Sometimes it is by studying pathological conditions that we discover the essential interactions that occur during tooth eruption. Frequently, a delayed tooth eruption (DTE) is the first, if not the only, expression of a local or general pathology. A DTE can affect directly the diagnosis, the treatment planning, or the timing of the orthodontic treatment. Therefore, it is essential for the orthodontist to identify the cause of a DTE for implementing the correct treatment.

\section{KEYWORDS}

Tooth eruption, genetic disease inborn, systemic disease, delayed tooth eruption

\section{INTRODUCTION}

Dental eruption is a unique physiological event; the tooth is the only organ to appear a few months or years after birth. This complex and finely regulated process influences the normal development of the craniofacial region.

In the 1980s, many teams looked at the mechanisms behind dental eruption; their work has highlighted complex interactions between osteoblasts, osteoclasts, and the dental follicle (DF), involving many genetic factors. These studies have opened the way for the discovery of multiple genetic, molecular, and tissue interactions that occur during dental eruption.

The study of genetic or acquired disorders has made it possible, among other things, to understand the mechanisms involved in

Address for correspondence:

Chloé Choukroune

150, rue Gallieni - 92100 Boulogne-

Billancourt - France

Email: chloe.choukroune@gmail.com

Article received: 20-04-2017. Accepted for publication: 18-05-2017.

This is an Open Access article distributed under the terms of the Creative Commons Attribution License (http://creativecommons.org/licenses/by/4.0), which permits unrestricted use, distribution, and reproduction in any medium, provided the original work is properly cited. 
dental eruption and has shown how these interactions are essential for the smooth running of the process. A disruption of the eruption process can occur in the context of systemic or genetic disorders; the clinical picture can range from a simple delay to a complete agenisis. Often, changes in the eruption process are the first, if not the only, manifestation of a systemic or genetic pathology. The precise identification of the cause of a disruption of the eruption process helps refine the diagnosis, define the overall treatment plan, and the orthodontic treatment schedule.

\section{ERUPTION STAGES}

Eruption is defined as the movement of the tooth germ from its site of development in the alveolar processes to its functional position in the oral cavity ${ }^{22}$. Before teeth achieve their functional placement on the arch, they undergo many movements. According to Ten Cate, these complex movements can be organized into three phases ${ }^{25}$ :

- Pre-eruptive movements: undergone by deciduous and permanent teeth within the tissues before the onset of eruption;

- Eruptive movements: when the tooth moves from its intraosseous position to its functional position on the arch. This phase can be divided into intra-alveolar and supra-alveolar eruption;

- Posteruptive movements: the tooth remains in its functional position and adapts to the growth of the jaw and proximal and occlusal wear.
Although the development of the craniofacial region is of interest to orthodontists, the clinical signs of systemic and genetic disorders responsible for eruptive disorders are still not fully understood by practitioners. This article summarizes the clinical signs of the main disorders presenting as eruption disorders after reviewing the mechanisms which affect eruption. This is to improve management and diagnosis so that treatments can be better adapted to meet the needs of patients and their families.

\section{Pre-eruptive phase}

Long before eruption, the tooth germ will undergo intra-alveolar movements during its development, which do not affect the direction of eruption ${ }^{6,7,45}$.

Because of the rapid development of the deciduous teeth (DT), their germs will overlap at a given moment within the maxillae. Maxillary growth will force the roots of the second deciduous molars to move backward the roots of the front teeth to move forward to prevent cluttering.

The permanent teeth (PT) germs are initially in the same bony crypt as the deciduous teeth but are located on their lingual slope ${ }^{25}$.

After DT eruption, PT occupy their own crypts. They will move considerably during growth, for example from a lingual position for premolar germs to a more 


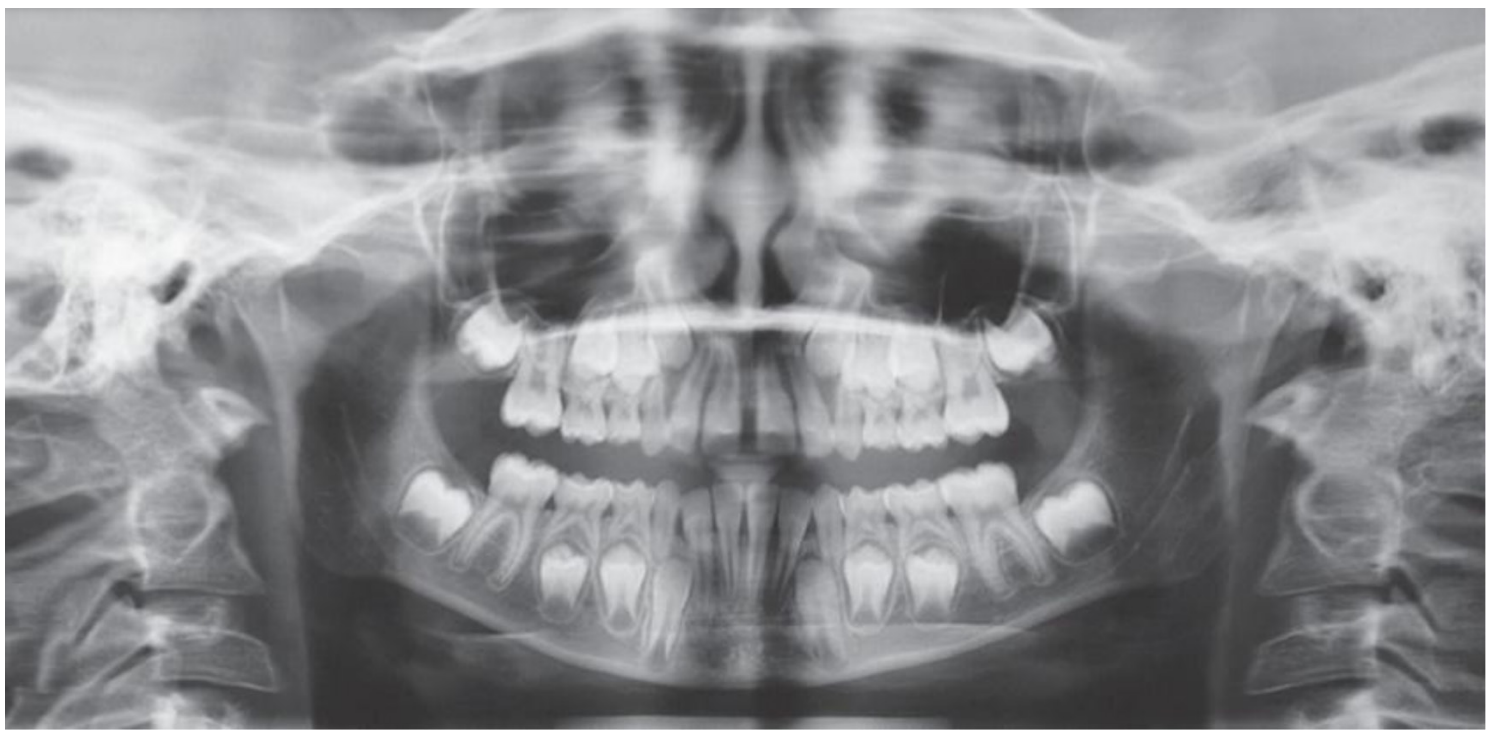

Figure 1

Panoramic view of a 9-year-old boy showing mandibular premolar germs located between the roots of deciduous molars. Note the mesial inclination of the second mandibular permanent molar (ODF service, Pitié-Salpêtrière Hospital).

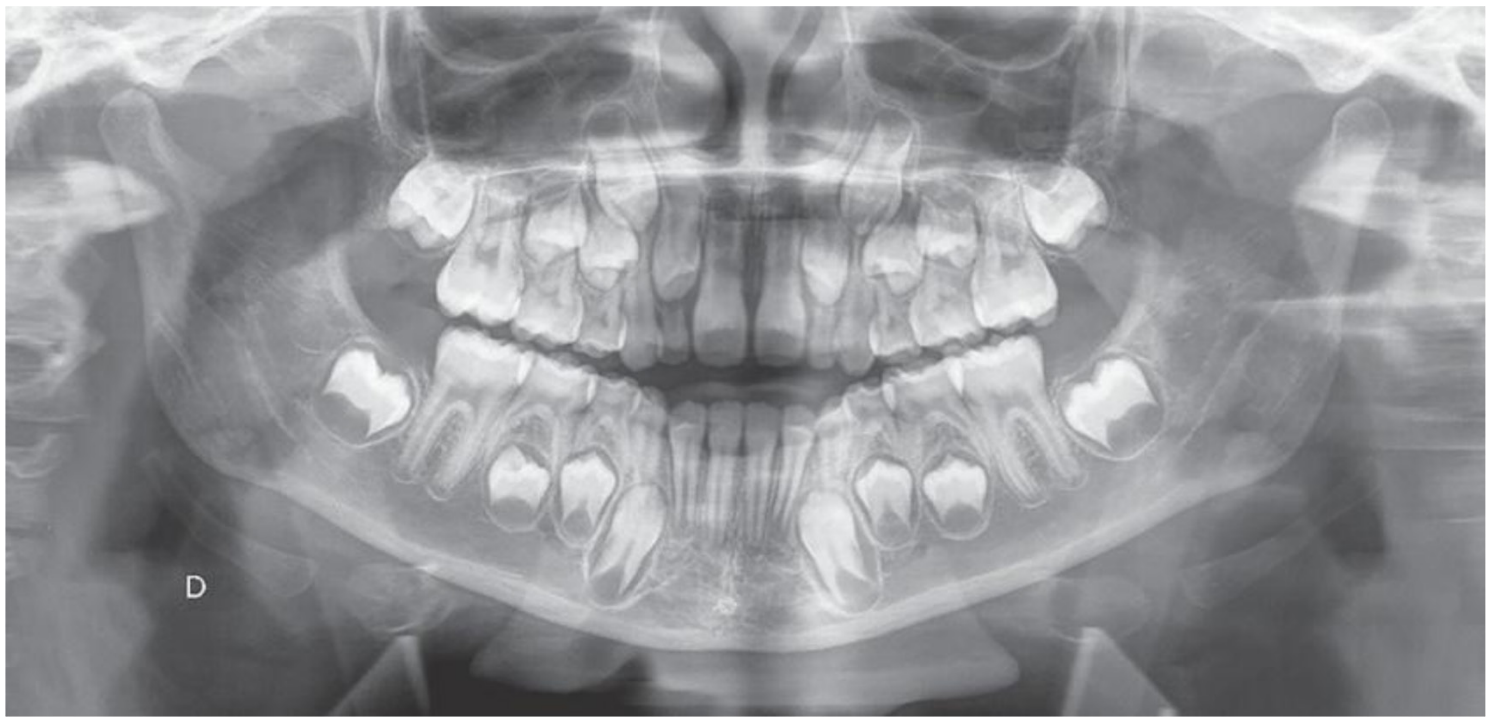

Figure 2

Panoramic view of a 9-year-old child showing bone resorption that occurs over 37/47 germs and the formation of an "eruption path" across the bone (ODF service, Pitié-Salpêtrière Hospital).

vestibular position between the roots of the deciduous molars (Figure 1).

These pre-eruptive movements aim to position the germ in its final position before initiating the eruptive movement. They result from the combination of two factors: on the one hand, the movements made by the germ itself, 
and on the other hand, the "passive" movements of the germ because of maxillary growth ${ }^{25}$. A lack of maxillary growth can disrupt these movements.

Few things are known about these pre-eruptive mechanisms and it is difficult to know if they are predetermined or if they represent an adaptive response. They are used to correctly position the germ and its bone crypt before the actual eruption begins ${ }^{6}$.

\section{Eruptive phase}

The eruptive phase can itself be divided into three stages: intraosseous phase, supraosseous phase, and posteruptive phase.

Intraosseous eruption begins as soon as crown formation is complete? It corresponds to the entire germ eruption phase through bone and occurs with mainly axial movements ${ }^{6}$ (Fig. 2).

It is similar for both teeth. Numerous other events accompany the intraosseous eruption of the germ: root elongation is initiated as well as the development of the periodontal ligament and the gingival junction.

\section{PHYSIOLOGY OF ERUPTION}

For over 70 years, multiple theories have been proposed to explain the eruptive phenomenon. It must be said that despite numerous studies and publications on the subject, the precise mechanism of the eruption is still unknown.

Eruption could be attributed to many factors that have been studied, approved, and then disapproved over time.
The supraosseous phase is the process by which the tooth emerges into the oral cavity. When the deciduous tooth falls out, the bone that surrounds the root is reabsorbed. With the eruption of the permanent tooth, the alveolar bone is reconstructed thanks to the osteogenic activity of the periodontal ligament. Then, the gingival defect is repaired progressively, and the alveolar process is built ${ }^{44}$.

When teeth appear in the oral cavity, they are subject to environmental factors such as the muscular pressures of the cheeks, tongue, and lips, as well as the eruptive forces of adjacent teeth, ${ }^{25}$ which will continue until the teeth reach their final position on the dental arch. The displacement of the teeth to the occlusal plane is ensured by root elongation and bone formation at the apical level and at the level of the inter-radicular septa ${ }^{22}$.

Finally, the posteruptive phase includes all movements made after the teeth have reached the occlusal plane. They include adaptive growth movements of the jaw as well as compensatory movements caused by occlusal and proximal wear.

The authors examined the proposed eruption mechanisms and tested multiple hypotheses:

- Collagen contraction of the periodontal ligament has been proposed to explain the eruptive phenomenon. However, no cause-effect relationship was found between the eruption rate and collagen turnover rate ${ }^{43}$. Many experiments have been performed in 


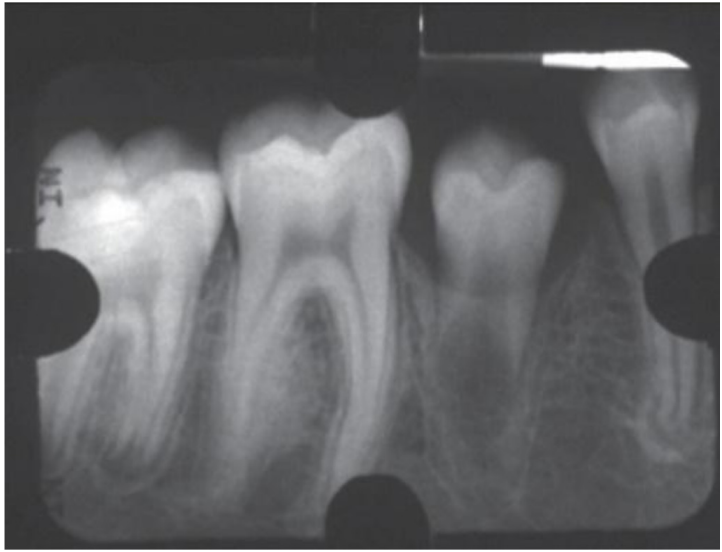

Figure 3

Tooth 45 having erupted in the absence of root elongation (ODF service, Pitié-Salpêtrière Hospital).

the presence of a collagen inhibitor and show that the teeth retain similar eruption rates ${ }^{42}$.

- It has also been hypothesized that vascular pressure may be responsible for the eruptive force. In 1985, authors drained the dental alveoli below the incisors of rats whose root ends had been removed. Therefore, increasing interstitial fluid pressure is impossible. They then observed a significant decrease in the rate of eruption and conclude that interstitial fluid pressure is necessary for the eruption ${ }^{2}$. To date, there is a lack of high-level studies to conclude that tissue and vascular pressure play a role in eruptive phenomena.

- The periodontal ligament was hypothetically implicated as well. Marks showed in his study that in individuals with osteopetrosis, the periodontal ligament is present, but the teeth do not erupt18. On the other hand, in individuals with type-I dentinal dysplasia (with teeth without roots and therefore no ligament), eruption still occurs.
This indicates that the root is not the motor of dental eruption (Fig. 3).

\section{Role of the dental crown}

Another hypothesis was that eruption depended on the dental organ itself, and particularly on the crown. A series of excellent experiments conducted by Marks and Cahill in the 1980s focused on showing the role of the crown and DF during eruption.

In one of their experiments, they show that DF is essential to the eruption, whereas the crown is not. Indeed, by replacing a premolar crown in dogs with a metal object, but leaving DF in place, the metal object still erupted. In contrast, in another study group, they removed DF and left the crown in place.

In this group, eruption did not occur and ankylosis plaques were identified around the germ ${ }^{19}$. They therefore concluded that the dental crown is absolutely unnecessary to the eruptive process. On the other hand, DF seems to play a primordial role and, in particular, a protective role.

In addition to the eruption of the metallic replica, the authors note the formation of an "eruption path" above the replica and basal bone apposition. This suggests that remodeling of the bone is also involved in dental eruption.

How is bone modeling involved during dental eruption and which parts depend on it?

\section{Role of DF}

In 1983, Marks et al. studied the cytology of the bone crypt and DF to qualify and quantify cell populations present before and during eruption ${ }^{21}$. 
Regarding the bone crypt, they found the following:

- During the pre-eruptive period: osteoblasts distributed on all surfaces of the crypt; osteoclasts present in small numbers and concentrated in the coronal region;

- During the eruption: abundant osteoblasts located in the basal and apical parts of the crypt; osteoclasts located almost exclusively in the coronal part of the bone crypt and exhibiting characteristics of osteoclastic activity;

- Monocytes (osteoclast precursors): located in the coronal part of the crypt; they were small at the start of eruption whereas they were large and adjacent to osteoclasts during eruption.

The populations of osteoclasts and monocytes increase simultaneously just before the eruption, coinciding with the start of eruption path formation.

Later, they show that DF monocytes appear through the bloodstream and then migrate into the bone crypt, where they fuse to form osteoclasts.

At the basal level of the germ, there is significant proliferative activity both in the follicle and in the adjacent bone ${ }^{54}$.

In an experiment conducted in the late 1980s, Marks and Cahill examine the effects of selectively removing certain parts of the follicle ${ }^{20}$. When the coronal portion of the follicle was removed, neither bone resorption nor eruption path formation occurred. In contrast, the eruption pathway formed when the basal portion of the follicle was removed, but no basal bone formation was detected.

Bone formation and resorption therefore occur independently of each other.
However, no part of the follicle can support the eruption alone.

The eruption is therefore a polarized phenomenon, coordinated by DF in time and space.

Recently, Sarrafpour et al. have proposed a new theory of eruption, in which DF is central to the initiation of the phenomenon ${ }^{36}$. Their theory is that the mastication forces between the bone and the soft tissues surrounding the erupting tooth lead to tissue remodeling, which results in tooth eruption. Therefore, dental tissues are supposed to be sensitive and able to respond to functional stress.

Using finite element analysis, they showed that DF is the most likely tissue to act as a mechanoreceptor. Their analysis also showed that DFs of the erupting teeth all undergo the same forces during mastication: the coronal part of DF experiences compressive forces whereas the basal part experiences tension forces. This is consistent with bone apposition/resorption observations in the basal and coronal parts of bone crypts during the intraosseous phase of eruption.

To conclude, Cahill and Marks, at the end of one of their experiments, expressed the idea that "the eruption consists of a series of metabolic events within the bone characterized by apposition and resorption coordinated by DF."

\section{Molecular aspects of the eruption}

Multiple processes and components are involved in triggering the bone resorption necessary for the formation of the eruption pathway. These have been discovered over several years of research and some signaling paths are still unclear. 
We can discuss the molecules acting directly on the formation of monocytes: CSF-131,52, MCP-131,32, and NF-kB ${ }^{30}$. Other molecules, such as PTH-rP28,55,56, RANKL $8,16,40,58$, IL-1 $\alpha^{47,53}$, or TGF- $\beta^{46,49}$, will act indirectly on monocyte recruitment by stimulating the expression of the above-mentioned molecules or by acting directly on the osteoclasts (Figure 4).

A small part of the research focused on the no less essential phase of bone formation occurring at the alveolar base during eruption. Osteogenic molecules have been highlighted, these are $B M P^{48,51,56,57}$, from $\operatorname{Run} \times 2^{50,59}$, or $\mathrm{MMP}^{4}$.

The design of a multifactorial eruptive process must include the following:

- A mechanism capable of allowing the germ to rise;

- A process of bone and periodontal remodeling during this movement and throughout life to maintain the functional integrity of the system;

- A process of tissue resistance during the upward movement.

Current and future research must take into account all these ideas to update the processes involved.

Although many advances have been made in understanding the eruption process, there are still many unclear areas. Is there a force which leads to eruption? What causes the tooth to erupt? What is the trigger for this movement? What are the phenomena responsible for supraosseous eruption and adaptation to occlusal wear throughout life?

The understanding of the eruptive phenomenon, sometimes through the observation of pathological conditions, will allow targeted treatments to be used in cases of eruption alterations.

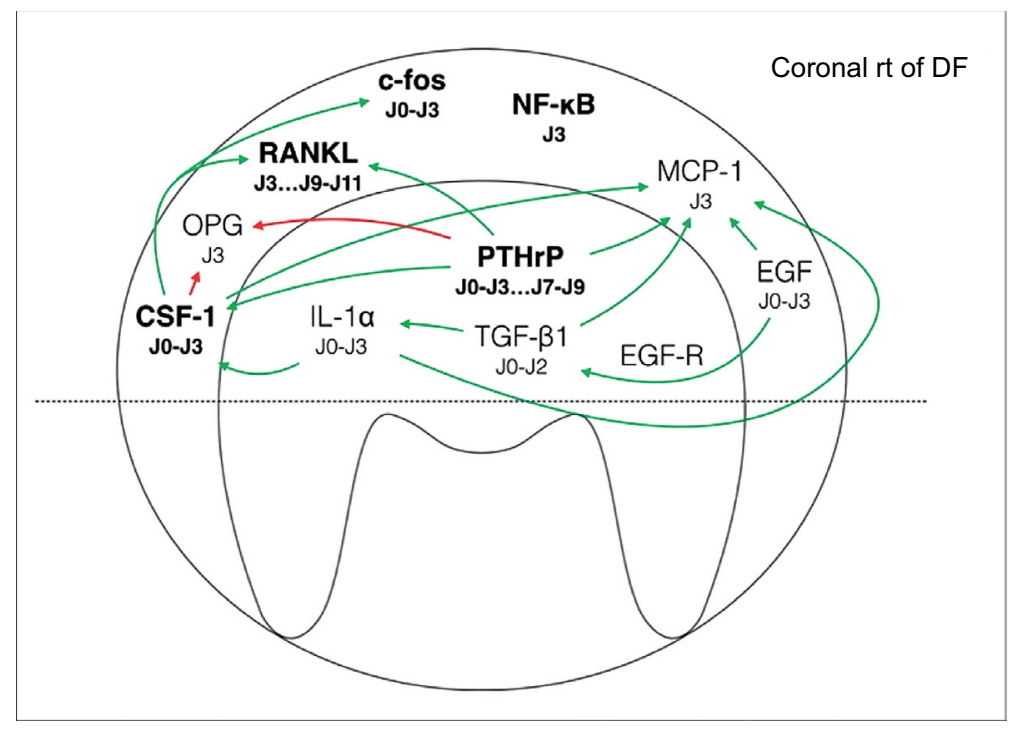

Figure 4

Diagram representing the main molecular components of the coronal part of DF during dental eruption. A green arrow indicates a stimulating action, a red arrow an inhibiting action. 


\section{PATHOLOGIES ASSOCIATED WITH ERUPTION DISORDERS}

Regularly, there is clinical evidence of deviations from the "normal" age of eruption. Although premature teeth eruption is observed occasionally, delayed eruption is observed most of the time.

Frequently, a delayed eruption is the first, or even the only, manifestation of a local or systemic pathology. A delayed eruption may directly affect the diagnosis, treatment plan, and orthodontic treatment schedule.

- The etiology is local when the eruption delays concern a tooth. These are the most common cases.

- When eruption delays concern a group of teeth or all the teeth, the etiology is systemic or genetic (associated or not associated with a syndrome).

\section{Systemic diseases associated with eruption disorders}

\section{Endocrinal disease}

Hypothyroidism, hypopituitarism, and hypoparathyroidism are endocrine disorders often associated with eruption delays ${ }^{41}$.

Hypothyroidism is an abnormality of thyroid metabolism characterized by a thyroid hormone deficiency. It affects $1 / 5,000$ to $1 / 10,000$ children in Europe. It includes in its symptomatology a densification of the skeleton affecting the long bones and the skull, a retardation of maturation and a varying scale of mental retardation ${ }^{5}$. The eruption of DT and PT is delayed, these teeth can also present anomalies in the enamel structure ${ }^{5}$.

Congenital pituitary insufficiencies (hypopituitarism) are characterized by superficial anomalies of the face (nasolabial cleft, frontal aplasia, nasofrontal plane angioma) and deep (velo-palatal cleft, choanal atresia) and dental anomalies (additional or missing teeth and enamel structure anomalies) ${ }^{5}$.

Children have delayed bone maturation, decreased skull base and facial bones, small sella turcica, a basicranial angle opening, facial retrognathism, decreased maxillary and mandibular dimensions, maxillary and mandibular retroposition, decreased lower facial height, increased mandibular divergence, as well as delayed tooth mineralization, maturation, and eruption ${ }^{5,15}$.

In practice, when faced with the discovery of facial and/or dental abnormalities in a small child, it is appropriate to ask for an endocrine assessment.

Growth hormone (GH) supplementation restores normal growth. However, it is possible that maxillomandibular imbalances will persist or worsen during treatment, requiring regular orthodontic follow-ups ${ }^{5}$.

\section{Drug treatments}

Many treatments, such as long-term chemotherapy or drugs that inhibit the prostaglandins pathway, can slow the rate of eruption by decreasing osteoclastic activity in periodontal tissues (aspirin, acetaminophen, ibuprofen, indomethacin, clodronate).

Bisphosphonate administration also causes a delayed eruption. Bisphosphonates are usually used in the treatment of certain bone cancers, osteogenesis imperfecta, and osteoporosis to decrease bone fragility. A study on rats confirmed that bisphosphonates cause eruption delays ${ }^{14}$. Some authors 
have reported an average delayed onset of eruption of 1.6 years in young patients treated with bisphosphonates ${ }^{11}$.

\section{PREMATURE BIRTH}

Delays in growth and dental development in premature infants have been identified by Seow and have been linked to DTE ${ }^{37}$.

In 2010, Aktoren et al. showed that children weighing $<2.5 \mathrm{~kg}$ at birth had an eruption delay of about 2 months compared to children weighing $<2.5 \mathrm{~kg}^{1}$.

In addition to the eruption delay, there are enamel abnormalities and maxillary growth defects notably related to intubation duration ${ }^{37}$.

\section{Malnutrition}

Chronic and prolonged malnutrition during childhood is linked to delays in eruption ${ }^{27}$. The authors report delays ranging from 1-4 months compared to normal eruption ages.
Vitamin deficiencies are also associated with eruption delays. In fact, rats for which vitamin A has been removed from the diet show eruption delays, the alveolar bone is delayed in its formation and the gingival tissues are hyperplastic ${ }^{38}$. According to Moulis et al., vitamin $A$ and $D$ (rickets) deficiencies are among the most common systemic causes of eruption delay in permanent dentition ${ }^{24}$.

\section{Genetic diseases associated with eruption disorders}

\section{Structural anomalies}

Hereditary amelogenesis imperfecta (HAl) is a group of inherited disorders that affect the enamel quantitatively and/or qualitatively. It exists in isolation or associated with certain syndromes. Most amelogenesis imperfecta are transmitted in an autosomal dominant fashion with variable severity.

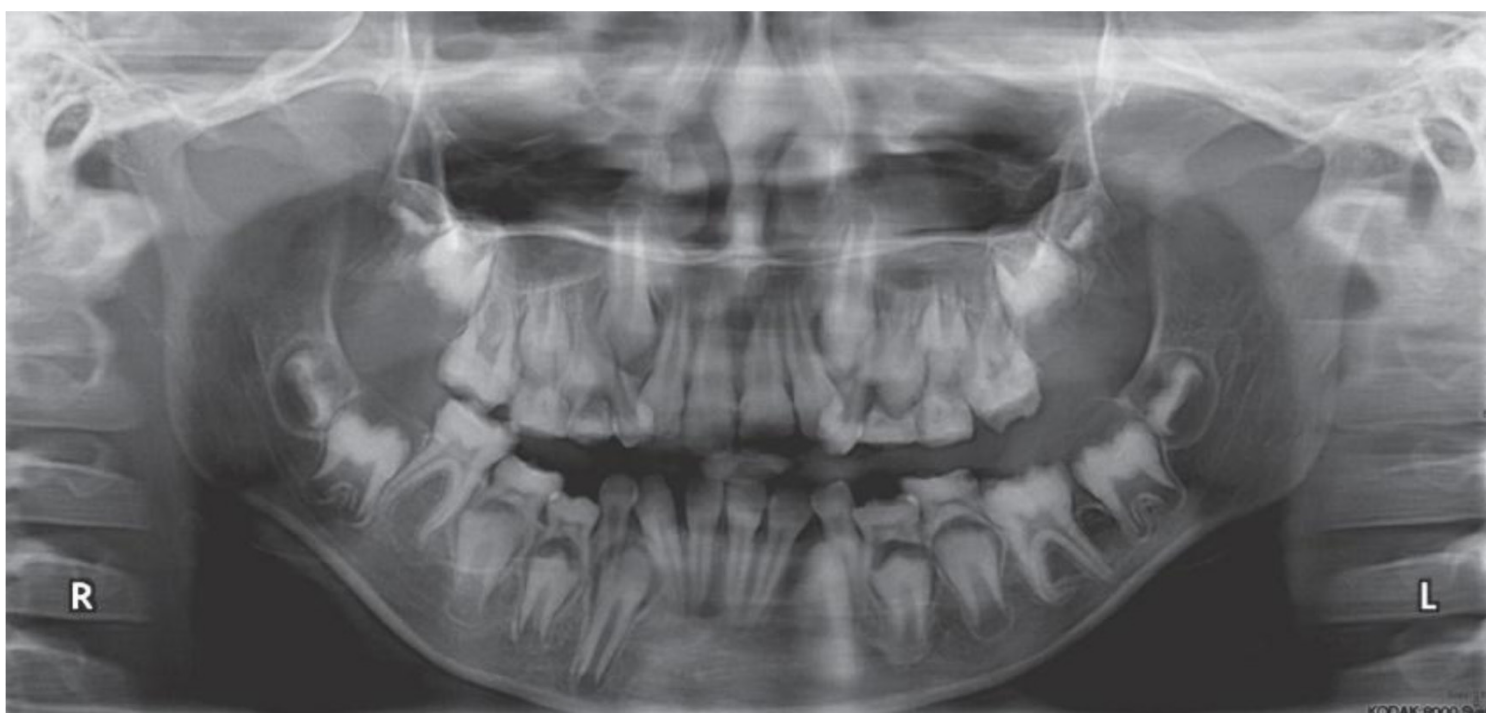

Figure 5

Panoramic view of a 9-year-old patient with hypocalcified amelogenesis imperfecta. We noted the eruption delay of 36 (courtesy of Dr. De La Dure Molla - Center of reference of malformations of the face, Rothschild Hospital). 
The multiplicity of clinical forms makes their classification difficult, but Witkop classification is commonly used to describe this disease ${ }^{23}$. The abnormalities are classified as hypoplastic, hypocalcified, or hypomatic.

HAl clinical forms can vary among families carrying different mutations of the same gene, within the same family, and even within a single dental arch between teeth from different areas.

Orally, $\mathrm{HAl}$ is accompanied by other abnormalities such as taurodontism, pulp calcifications, eruption defects, skeletal abnormalities (open bite, class III, etc.; Figure 5). One study identified the anomalies associated with $\mathrm{HAl}$ in 1999, Seow, cited by these authors, assessed the risk of delayed eruption in HAl patients as six times higher compared to the healthy population. Cases with the most severe eruption delays were associated with recessive hypoplastic forms of $\mathrm{HAl}^{9}$.

\section{- Dentinogenesis imperfecta (DI) associated with osteogenesis imperfecta}

Osteogenesis imperfecta $(\mathrm{Ol}$ ) is a heterogeneous group of genetic diseases characterized by bone fragility, low bone mass, and a tendency for fractures of varying severity.

Dental manifestations include: posterior open bite, bulbous teeth, pulpal obliterations, short and fine roots, brown or gray discolorations of the crown, bluish tint when $\mathrm{Ol}$ is associated with DI, ectopic eruptions or molar impactions, and agenesis. Very frequently, in all types of Ol, a class III is present, more or less associated with anterior open bite and/or laterally inverted articulations ${ }^{3,17}$.
O'Connell et al. report a delay in dental maturation of $>12$ months in $21 \%$ patients with type-3 Ol, whereas patients with type-4 Ol exhibit an acceleration of dental development ${ }^{26}$.

\section{Syndromes}

Many syndromes are associated with eruption delays in permanent dentition ${ }^{24}$.

- Down syndrome or trisomy 21;

- Turner syndrome (XO);

- Gardner syndrome or familial adenomatous polyposis;

- Cleidocranial dysostosis or PierreMarie Foy and Sainton's disease;

- Anhidrotic ectodermal dysplasia or Christ-Siemens-Touraine disease;

- Hutchinson-Gilford syndrome or progeria (dwarfism and pseudosenility, often associated with dental delays, dentinal dysplasias and abnormal position, dysplasia);

- Bloch-Sulzberger syndrome or Incontinentia pigmenti: a condition that is transmitted according to the dominant $X$-linked mode and associates dental delays with oligodontia;

- Apert syndrome or acrocephalosyndactylyia: associated craniosynostosis, syndactlylia of the feet and hands, various synostoses, as well as frequent dental congestion;

- Axenfeld-Rieger Syndrome: associated oligodontia, multiple dental delays and primary mesodermal dysgenesis of the iris.

\section{Primary failure of eruption (PFE)}

The term PFE, was first proposed by Proffitt and Vig in 1981 following a finding of posterior open bites in several patients ${ }^{29}$. It attests to a nonsyndromic 

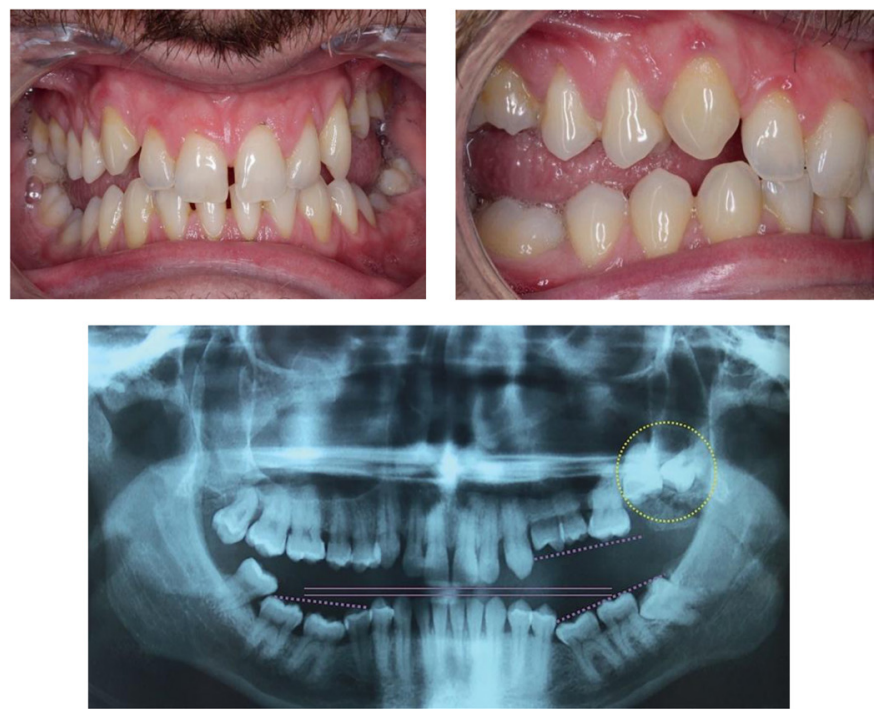

Figure 6

33-year-old patient with DPE.

The gap is not due to lingual interposition (ODF service, Pitié-Salpêtrière Hospital).

state in which the tooth fails to erupt. The tooth/teeth concerned is (are) not ankylosed, but its (their) eruption is not due to a malfunction of the eruption mechanism.

The eruption path forms well but the tooth does not erupt, or only partially. It suddenly stops its movement and is sometimes submerged or "reincluded"39

The diagnosis is made on the basis of the following symptoms:

- The posterior teeth are most often affected;

- The teeth posterior to the first affected tooth are generally affected;

- The eruption path is formed but eruption fails or only partially erupts;

- DTs and PTs can both be affected;

- The issue may be symmetrical or asymmetrical;

- The affected teeth are not ankylosed, but tend to become ankylosed when applying an orthodontic traction force.
The result of these eruption defects is severe lateral obstruction and growth of the alveolar process is deficient on the affected side (Fig. 6).

Note that deciduous teeth are often ankylosed and a family history of eruption failure is present in many cases ${ }^{35}$.

Case analysis suggested autosomal dominant familial transmission with variable penetrance.

In 2008, a team discovered a mutation of the PTH1R gene in 15 distinct patients. The nonsyndromic mutation results in a truncated $\mathrm{PTH} 1 \mathrm{R}$ receptor leading to premature degradation of the dysfunctional receptor. The haploinsufficiency of the PTH1R receptor would therefore be the mechanism behind DPE ${ }^{10}$. To date, there are 14 mutations of PTH1R associated with DPE ${ }^{34}$.

There is no explanation for the fact that posterior teeth are preferentially affected, although the authors assume a chronologically and spatially regulated expression of $\mathrm{PTH} 1 \mathrm{R}$ during eruption ${ }^{13}$. They do not exclude any 
other genes that may be involved with DPE.

It is important to make the differential diagnosis between DPE and ankylosis. It can be accomplished with three-dimensional (3D) imaging, which greatly improves the visibility of pathological areas compared to two-dimensional (2D) radiography. In fact, only a genetic test for PTH1R mutations can identify with certainty the presence of DPE ${ }^{33}$.

This will prevent the orthodontist from implementing a long and difficult treatment that will inevitably fail, as teeth affected by DPE will become ankylosed and will affect the rest of the

\section{CONCLUSION}

Dental eruption is a very finely regulated process. DF is a major component and many genes, molecules, and cells participate in this process.

Eruption theories are unanimously agreed upon: osteolysis is necessary for successful dental eruption. Research has focused on this essential phase of the eruption process, highlighting the many molecules needed, coming into play at different stages, sometimes redundantly. We can discuss the molecules acting directly on the recruitment of monocytes (osteoclast precursors): CSF-1, MCP-1, and NF- $\mathrm{BB}$. Other molecules, such as PTHrP, RANKL, IL-1a, or TGF- $\beta \beta$, will act indirectly on monocytotic recruitment by stimulating the expression of the aforementioned molecules or by acting directly on the osteoclasts.

A small part of the research focused on the no less essential phase of bone formation occurring at the base of the arch if the chosen technique is a multifastening/straight arch technique.

The infraocclusion generated by DPE causes significant aesthetic and functional damage. Using orthodontic forces on teeth with DPE leads to failure. The choice of treatment for DPE is therefore complex.

To date, few therapeutic options exist to date to improve occlusion in patients with DPE. The options are the following: therapeutic abstention for the mildest cases, prosthetic (onlay, removable, or fixed prosthesis), or implant restorations ${ }^{12}$, or as a last resort, vertical segmental osteotomies.

alveolus during eruption. Osteogenic molecules have been highlighted: they are BMP, Runx2, or MMP.

In the end, very few studies have been conducted on the supraosseous phase of eruption, although this is a crucial stage in the process. Some authors have suggested the involvement of the desmodontal ligament, a structure derived from DF.

Dental eruption can sometimes present chronological anomalies. It can be delayed or completely interrupted. Etiologies can be local (not detailed in this work), systemic, or genetic.

The orthodontist is involved in the early detection of eruption delays, which improves treatment success rates. The cause of abnormal eruption should always be sought, and the patient referred to a geneticist if a doubt arises.

Current treatments are limited to a purely mechanical traction of the in- 
cluded teeth or a delayed eruption. However, recent advances in molecular biology promise hope for a change in the practices of orthodontists. The research avenues opened by the understanding of the pathologies associated with eruption delays make it possible to foresee new modes of treatment in which genetic and/or molecular treatments would fit into the treatment process.

Conflict of interest: The author declares that there is no conflict of interest.

\section{BIBLIOGRAPHY}

1. Aktoren O, Tuna EB, Guven Y, Gokcay G. A study on neonatal factors and eruption time of primary teeth. Community Dent Health 2010;27(1):52-56.

2. Aladdin QI, Burn-Murdoch RA. The effect of proce - hard intended to alter the interstitial fluid pressure in the sockets of resected rat incisors we their eruption rate. Arch Oral Biol 1985;30(7):525-530.

3. Bailleul-Forestier I, Berdal A, Vinckier F, Ravel T, Fryns JP, Verloes A. The genetic basis of inherited anomimies of the teeth. Part 2Syndromes with significant dental involvement. Eur J Med Genet 2008;51(5):383-408.

4. Bartlett JD, Zhou Z, Skobe Z, Dobeck JM, Tryggvason K. Delayed tooth eruption in membrane type-1 matrix metalloproteinase deficient mice. Connect Tissue Res 2003;44 Suppl 1:300-304.

5. Besson A, Menuelle P, Ferri J, Berdal A. Dr. Richard - pathies and cranio-facial discrepancies: interest to the orthodontist. Part three. Int Orthod 2007;5(1):3-15.

6. Bhaskar SN. Orban's oral histology and embryology. Saint LouisMosby-Year Book, 1991.

7. Carlson H. Studies on the rate and amount of eruption of certain human teeth. Am J Orthod Oral Surg 1944;42:78-91.

8. Castaneda $\mathrm{B}$, et al. Bone resorption control of tooth eruption and root morphogenesis: Involvement of the receptor activator of NF-kB (RANK). J Cell Dec 2011;226(1):74-85.

9. Collins MA, Mauriello SM, Tyndall DA, Wright JT. Dental abnormalities associated with amelogenesis imperfecta: a radiographic assessment. Oral Oral Surg Med Oral Oral Pathol Radiol Endod 1999;88(3):358-364.

10. Decker $E$, et al. PTHR1 loss-of-function mutations in familial, nonsyndromic primary failure of tooth eruption. Am J Hum Genet 2008;83(6):781-786.

11. Denden N. Eruption disorders of permanent second molars.2015.

12. Frazier-Bowers SA, CP Puranik, Mahaney MC. The etiology of eruption disorders - further evidence of a "genetic paradigm." Semin Orthod 2010;16(3):180-185.

13. Frazier-Bowers SA, Simmons D, Wright JT, Ackerman JL, Proffit WR. Primary failure of eruption and PTH1R: the importance of a genetic diagnosis for orthodontic treatment planning. Am J Orthod Dentofacial Orthop 2010;137 (2):160.e1-7; discussion 160-161.

14. A Kamoun-Goldrat, Ginisty D, lemon M. Effects of bisphosphonates on tooth eruption in children with osteogenesis imperfecta. Eur J Oral Sci 2008;116(3):195-198. 
15. Kjellberg $H$, Beiring $M$, Albertsson Wikland K. Craniofacial morphology, dental occlusion, tooth eruption, and dental maturity in boys of short stature with or without growth hormone deficiency. EUR J Oral Sci 2000;108(5):359-367.

16. Kong YY, et al. OPGL is a key regulator of osteoclastogenesis, lymphocyte development and lymph node organogenesis. Nature 1999;397(6717):315-323.

17. Malmgren $B$, Norgren $S$. Dental aberrations in children and adolescents with osteogenesis imperfecta. ACTA Odontol Scand 2002;60(2):65-71.

18. Marks SC. Osteoclast biology: lessons from mammalian mutations. Am J Med Genet 1989;34(1):43-54.

19. Marks SC, Cahill DR. Experimental study in the dog of the nonactive role of the tooth in the eruptive process. Arch Oral Biol 1984;29(4):311-322.

20. Marks SC, Cahill DR. Regional control by dental following of alterations in alveolar bone metabolism during tooth eruption. J Oral Pathol 1987;16(4):164-169.

21. Marks SC, Cahill DR, Wise GE. The cytology of the dental follicle and adjacent alveolar bone during tooth eruption in the dog. Am J Anat 1983;168(3):277-289.

22. Marks SC, Schroeder HE. Tooth Eruption: Theories and Facts. Anat Rec 1996;245 (2): 374-393.

23. Molla M, Bailleul-Forestier I, Artaud C, Verloes A, Naulinlfi C. Odontogenetics. EMC Oral Medicine, 2008.

24. Moulis E, Thierrens CFD, Goldsmith TM, Torres JH. Anomalies of the eruption. Http://www.em-Premiumcomdatatraitespem04-931499. http://www.em-premium.com. rproxy.sc.univ-paris-diderot.fr/article/15429/resultatre-cherche/1Accessed August 31, 2015.

25. Nanci A, Ten Cate AR. Ten Cate's Oral Histology: Development, Structure, and Function. 8th ed. St. Louis, Mo. Elsevier, 2013.

26. O'Connell AC, Marini JC. Evaluation of oral problems in an osteogenesis imperfecta population. Oral Oral Surg Med Oral Oral Pathol Radiol Endod 1999;87(2):189-196.

27. Peedikayil, Faizal C. Delayed tooth eruption. EJ Dent 2011;1(4):81-86.

28. Philbrick WM, Dreyer BE, Nakchbandi, Karaplis AC. Parathyroid hormone-related protein is required for eruption. Proc Natl Acad Sci USA 1998;95(20):11846-11851.

29. Proffit WR, Vig KW. Primary failure of eruption: a possible cause of posterior open-bite. Am J Orthod 1981;80(2):173-190.

30. That BG, Lumpkin SJ, Wise GE. Implications for the Interaction of the Interactions of Nuclear Interactions with Nuclear Factor-kappaB gene expression in the dental rat follicle. Arch Oral Biol 1999;44(11):961-967.

31. That BG, Wise GE. Colony-stimulating factor-1 and monocyte chemotactic protein-1 chemotaxis for monocytes in the dental rat follicle. Arch Oral Biol 1997;42(12):855-860.

32. That BG, Wise GE. Tooth eruption molecules enhance MCP-1 gene expression in the dental follicle of the rat. Dev Dyn 1998;212(3):346-351.

33. Raberin M, Diesmusch C, Cordier M-P, Farges J-C. Innovations dans le diagnostic et le traitement d'un cas de défaut primaire d'éruption lié à une mutation du gène PTHR1Orthod en 2015;86(3):221-231.

34. Risom L, et al. Identification of six novel PTH1R mutations in families with a history of primary failure of tooth eruption. PLoS One 2013;8(9):e74601. 
35. Sakaguchi K, Yagi T, Nagata J, Kubota T, K Sugihara, Miyawaki S. Patient with oculo-faciocardio-dental syndrome treated with surgical orthodontics. Am J Orthod Dentofacial Orthop 2012;141(4_Suppl):S159-170.

36. Sarrafpour B, Swain M, Li Q, Zoellner H. Tooth eruption results from bone remodeling driven by dick forces sensed by soft tissue dental follicles: a finite element analysis. PLoS One 2013;8(3):e58803.

37. Seow WK. Effects of Preterm Birth on Oral Growth and Development. Aust Dent J 1997; 42(2):85-91.

38. Shafer WG. Textbook of Oral Pathology. 4th edition. Philadelphia: WB Saunders Co., 1983.

39. Stellzig-Eisenhauer A, et al. Primary defect of eruption (DPE). Clinical and molecular genetic analysis. Orthod Fr 2013;84(3):10.

40. Sun $\mathrm{H}$, et al. Ophthalmic regulation of OPG and RANKL in human osteoclastogenesis. Cell Tissue Res 2015;362(2):399-405.

41. Suri L, Gagari E, Vastardis H. Delayed tooth eruption: pathogenesis, diagnosis, and treatment. LITERATURE REVIEW Am J Orthod Dentofacial Orthop 2004;126(4):432-445.

42. Thomas N. Collagen as the Generator of Tooth Eruption. In: The Eruption and Occlusion of Teeth. Poole, DFG and Stack MV. London: Butterworths, 1976.

43. Van den Bos T, Tonino GJ. Composition and- metabolism of the extracellular matrix in the periodontal - liga lies impeded and unimpeded of rat incisors. Arch Oral Biol 1984;29(11): 893-897.

44. Van Der Linden F. Development of the Human Dentition (iBook). http://www.quintpub. com/display_detail.php3?psku=B5242\#.VZID72DNA1wPublished 2013. Accessed July 5, 2015.

45. Weinmann J. Bone changes related to the eruption of the teeth. Angle Orthodon 1944: 11:83-99.

46. Wise G, Lin F, S Marks, Gorski J. The molecular basis of tooth eruption. In: Of eruption, resorption and replacement by implants. International Conference (Sheraton Tara Hotel and Resort, Danvers, Massachusetts). In: Ze'ev Davidovich; 1994.

47. Wise GE. In vivo effect of interleukin-1 alpha on colony-stimulating factor-1 gene expression in the dental follicle of the rat molar. Arch Oral Biol 1998;43(2):163-165.

48. Wise GE, Ding D, Yao S. Regulation of secretion of osteoprotegerin in rat dental follicle cells. EUR J Oral Sci 2004;112(5):439-444.

49. Wise GE, Fan W. Immunolocalization of transforming growth factor beta in rat molars. J Oral Pathol Med 1991;20(2):74-80.

50. Wise GE, Frazier-Bowers S, D'Souza RN. Cellular, molecular, and genetic determinants of tooth eruption. Crit Rev Oral Biol Med 2002;13(4):323-334.

51. Wise GE, He H, Gutierrez DL, Ring S, Yao S. Requirement of alveolar bone training for eruption of rat molars. Eur J Oral Sci 2011;119(5):333-338.

52. Wise GE, Lin F. Regulation and localization of colony stimulating factor-1 mRNA in cultured rat dental follicle cells. Arch Oral Biol 1994;39(7):621-627.

53. Wise GE, Lin F, Zhao L. Immunolocalization of interleukin-1 alpha in rat mandibular molars and its enhancement after in vivo injection of epidermal growth factor. Cell Tissue Res 1995;280(1):21-26.

54. Wise GE, Marks SC, Cahill DR. Ultrastructural features of the dental follicle associated with training of the tooth eruption pathway in the dog. J Oral edition 1985;14(1):15-26. 
55. Wise GE, as the BG, Huang H, Lumpkin SJ. Enhancement of gene expression in rats dental follicle cells by parathyroid hormone-related protein. Arch Oral Biol 2000;45(10): 903-909.

56. Yao S, Pan F, Wise GE. Chronological gene expression of parathyroid hormone-related protein $(\mathrm{PTHrP})$ in the rat stellate reticulum: implications for tooth eruption. Arch Oral Biol 2007;52(3):228-232.

57. Yao S, Prpic V, Pan F, Wise GE. TNF-alpha upregulates expression of BMP-2 and BMP-3 genes in the male rat follicle-implications for tooth eruption. Connect Tissue Res 2010;51 (1):59-66.

58. Yao S, Ring S, HenkWG, Wise GE. In vivo expression of RANKL in the dental rat follicle as determined by laser capture microdissection. Arch Oral Biol 2004;49(6):451-456.

59. Yoda S, Suda N, Kitahara Y, Komori T, Ohyama K. Delayed tooth eruption and suppressed osteoclast number in the eruption pathway of heterozygous Runx2/Cbfa1 knockout mice. Arch Oral Biol 2004;49(6):435-442. 